\title{
Ectodermal Dysplasia presenting with Atrophic Rhinitis: A Report of Two Cases and a Review of the Literature
}

\author{
${ }^{1}$ Sampurna Pati, ${ }^{2}$ Sudipta Pal, ${ }^{3}$ Somnath Saha, ${ }^{4}$ Surajit Biswas
}

\section{ABSTRACT}

Aims: To present two rare cases of ectodermal dysplasia presenting with maggot infestation due to atrophic rhinitis.

Study design: Case report.

Setting: A tertiary care referral hospital.

Presentation: Two male children aged about 5 and 8 years presented to the ear, nose, and throat emergency with a history of maggot infestation of the nose.

Results: Clinical examination was suggestive of ectodermal dysplasia. Intranasal examination was suggestive of atrophic rhinitis. Maggots were removed in the conventional manner. Following a conservative treatment, skin biopsy and nasal mucosal biopsy were done, which confirmed the diagnosis of ectodermal dysplasia.

Conclusion: Any ectodermal dysplasia patient should be suspected of having atrophic rhinitis and intranasal conservative therapy should be initiated at the earliest to prevent complications like maggots in the nose.

Keywords: Atrophic rhinitis, Ectodermal dysplasia, Nasal myiasis.

How to cite this article: Pati S, Pal S, Saha S, Biswas S. Ectodermal Dysplasia presenting with Atrophic Rhinitis: A Report of Two Cases and a Review of the Literature. Clin Rhinol An Int J 2016;9(1):53-55.

Source of support: Nil

Conflict of interest: None

${ }^{1}$ Consultant, ${ }^{2}$ Assistant Professor, ${ }^{3,4}$ Professor

${ }^{1}$ Department of ENT, Nova Superspecialty Hospital Hyderabad, Andhra Pradesh, India

${ }^{2}$ Department of ENT, Calcutta National Medical College Kolkata, West Bengal, India

${ }^{3}$ Department of ENT, Nil Ratan Sircar Medical College and Hospital, Kolkata, West Bengal, India

${ }^{4}$ Department of Dermatology, RG Kar Medical College and Hospital, Kolkata, West Bengal, India

Corresponding Authors: Sudipta Pal, Assistant Professor Department of ENT, Calcutta National Medical College Mankundu, Kolkata, West Bengal, India, Phone: +919051757391 e-mail: drsudiptapal@gmail.com

Somnath Saha, Professor, Department of ENT, Nil Ratan Sircar Medical College and Hospital, Kolkata, West Bengal, India Phone: +919830642186, e-mail: sreekar_saha@hotmail.com

\section{INTRODUCTION}

Sir Charles Darwin had mentioned in his book "The Variation of Animal and Plants under Domestication" about an Indian family with defective dentition and the inability to sweat properly in 1838. Although Thurnam ${ }^{1}$ published the first report of a patient with ectodermal dysplasia in 1848, the term "ectodermal dysplasia" was not coined until 1929 by Weech. ${ }^{2}$ Ectodermal dysplasia comprises of a large group of 192 distinct inherited disorders that are clinically and genetically heterogeneous with the common features of abnormal, absent, or delayed embryonic development of one or more of the epidermal and mucosal appendages. Among them the most common disorders is hypohidrotic or anhidrotic ectodermal dysplasia (Christ variety), which has an estimated prevalence of 1 per 100,000 births. ${ }^{3}$ The clinical triad of this disorder consists of hypotrichosis, anodontia or hypodontia, and hypohidrosis or anhidrosis.

\section{CASE PRESENTATION}

An 8-year-old boy attended the ear, nose, and throat (ENT) emergency with the complaint of live insects coming out of his nose; he also had fever and general weakness. Detailed history was taken from his mother, who revealed that her son suffered from recurrent attacks of high fever and heat intolerance along with occasional epistaxis, anosmia, and purulent discharge from the nose. He had frontal bossing with sparse thin hair on the scalp and eyebrows, saddle nose, and only three conical teeth (Figs 1 and 2). His developmental milestones and IQ level were in the normal range. Anterior rhinoscopy showed lots of crusting in the nasal cavity with maggots and with atrophic turbinates. Thermoregulation was achieved after admission and maggots were removed. Skin biopsy was performed, which revealed absence of eccrine sweat glands, and biopsy from nasal mucosa showed the absence of mucous glands (Figs 3 and 4). Thus, the child was diagnosed to be suffering from the rare disorder anhidrotic ectodermal dysplasia. He had no family history of a similar disease, and his male sibling was not affected.

A second similar case of maggots in the nose that presented to our department was that of a 5-year-old boy who came from a remote village with nasal myiasis 


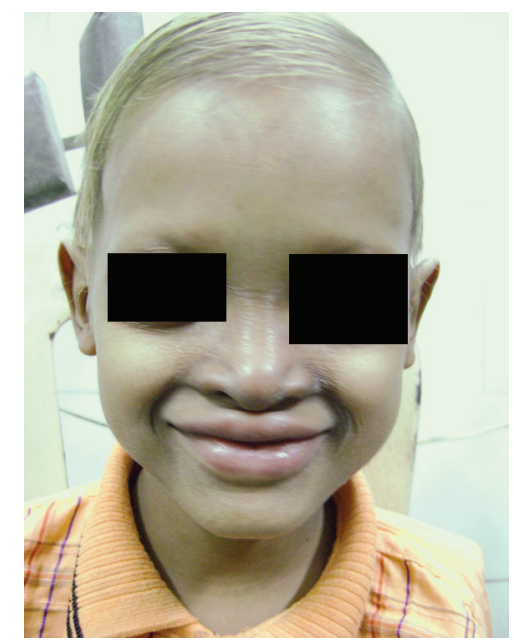

Fig. 1: Clinical photograph of the 1st patient

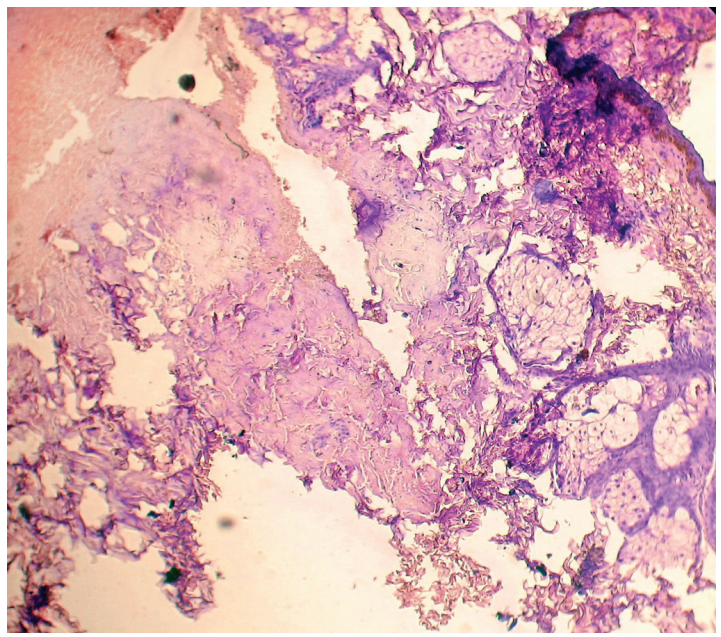

Fig. 3: Histopathological slide from skin biopsy showing absence of eccrine glands

and bilateral ear discharge. His body temperature was $103^{\circ} \mathrm{F}$, and he was in a very irritable state. After admission, the maggots were removed and thermoregulation restored by repeated cold sponging. He had the same facies as the previous case but with complete alopecia and very dry skin. Interestingly, his mother also had sparse thin hair, dry skin, and the inability to sweat properly (Fig. 5).

\section{DISCUSSION}

Most of the patients of ectodermal dysplasia attend a dermatology or dental clinic first. But these rare cases may present with otorhinological manifestations as the chief complaint and must be diagnosed by the clinical features and proper history-taking. The clinical features are not evident in neonates. Dental, hair, and nail anomalies become evident only in early childhood. Other signs and symptoms include xerophthalmia, ${ }^{4}$ xerostomia, ${ }^{5}$ frequent otitis, rhinitis, pharyngitis, ${ }^{6,7}$

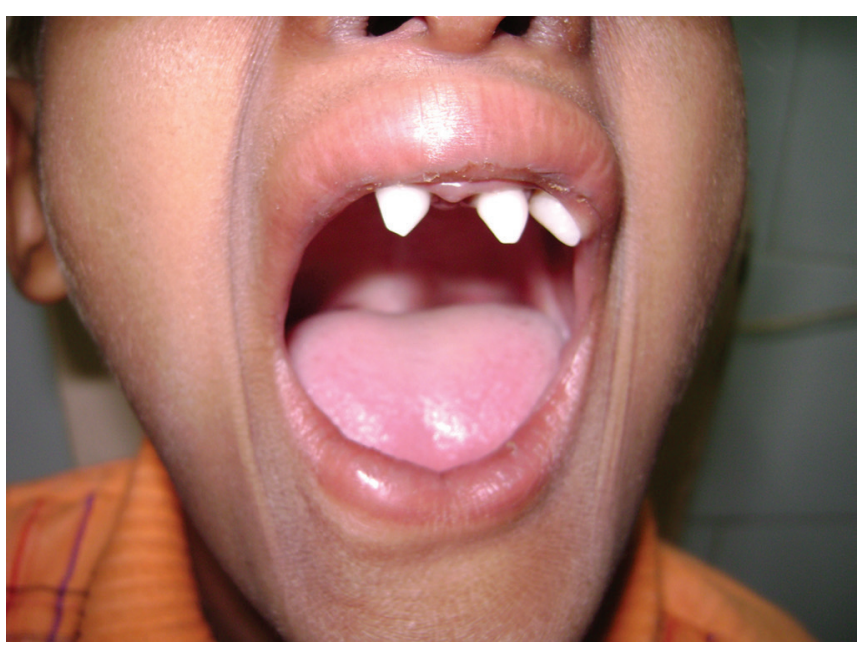

Fig. 2: Conical teeth of the 1st patient

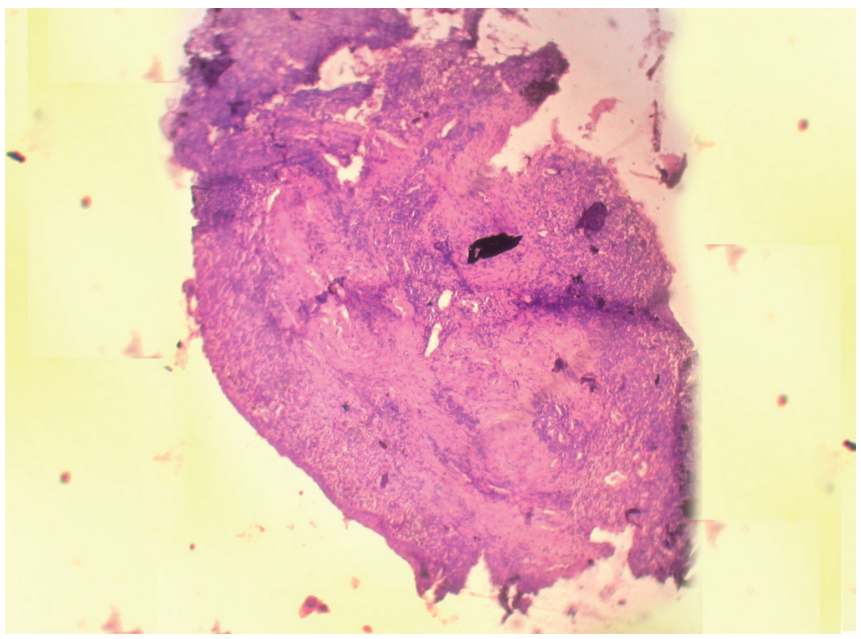

Fig. 4: Nasal mucosal histopathology slide showing absence of mucous glands

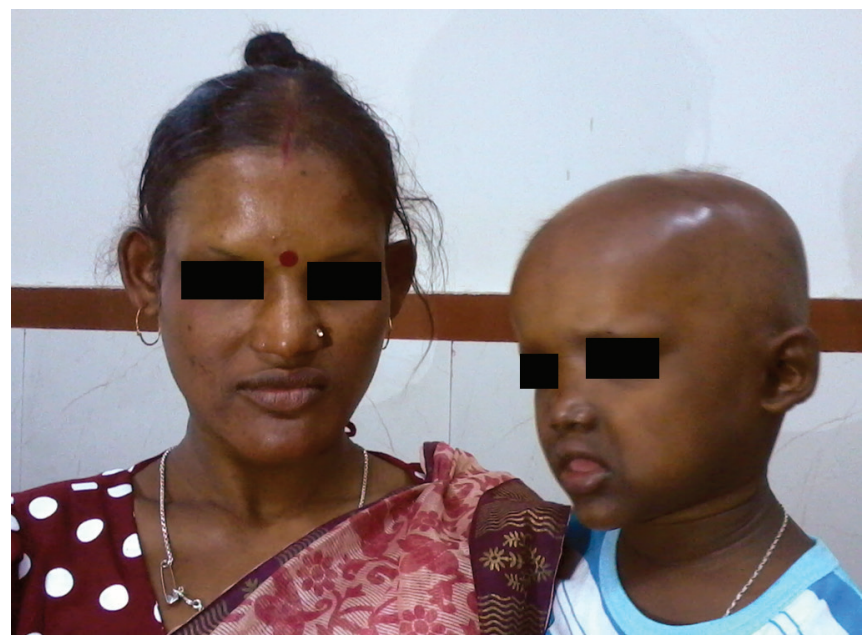

Fig. 5: Clinical photograph of the second patient with his mother

growth failure, ${ }^{8}$ etc. Hypoplasia, or the absence of mucous glands in the upper aerodigestive tract, is responsible for these manifestations. Till now, only few cases have presented with nasal symptoms. ${ }^{9-13}$ 
For anhidrotic or hypohidrotic ectodermal dysplasia, the inheritance pattern is almost always $X$-linked recessive. Three genes that are related to the ectodysplasin protein and its receptor have been identified in the $\mathrm{X}$ chromosome at the $\mathrm{q} 13$ position. Like all other $\mathrm{X}$-linked recessive disorders, only male children will manifest the disease and female carriers will be asymptomatic. But carrier females may sometimes show partial manifestation of the disease, which can be explained by lionization or inactivation of one of the $\mathrm{X}$ chromosomes. ${ }^{14}$ That is why the mother of the second child in our case was mildly affected and the child being a male suffered from the whole stigmata of the disorder. But the same is not true for the first case because neither his mother nor his brother showed any features suggestive of this rare disorder. This must be a case of autosomal dominant inheritance. The gene for autosomal dominant hypohidrotic ectodermal dysplasia has been mapped to 2q11-q13.

Ectodermal dysplasia is a nonprogressive disorder with good prognosis. Morbidity can be decreased with orthodontic reconstruction; proper care of nose, ears, and oral cavity; and maintaining body temperature by lifestyle modification. There are several other forms of the disorder that need special attention like anhidrotic ectodermal dysplasia with immunodeficiency, which may give rise to recurrent systemic infection. Hidrotic ectodermal dysplasia patients may suffer from eye changes like cataract or strabismus. An erosive scalp dermatitis may be seen in AEC syndrome (ankyloblepharon, ectodermal dysplasia, cleft lip/palate), whereas ectrodactyly is pathognomonic in EEC syndrome (ectodermal dysplasia, ectrodactyly, cleft lip/palate). Carrier mother must be counseled about the risk in male child. Prenatal diagnosis is possible by fetal skin biopsy or by linkage analysis.

\section{CONCLUSION}

Ectodermal dysplasia is a rare entity that can first present to the ENT clinic with atrophic rhinitis, nasal myiasis, or recurrent ear infection. Proper history-taking, general examination, and family history are the cornerstones of the diagnosis. Otorhinolaryngologists play a vital role in the health care team managing such patients.

\section{REFERENCES}

1. Thurnam J. Two cases in which the skin, hair and teeth were very imperfectly developed. Med Chir Trans 1848;31: 71-82.

2. Weech AA. Hereditary ectodermal dysplasia (congenital ectodermal defect). Am J Dis Child 1929;37:766-790.

3. Stevenson AC, Kerr CB. On the distribution of frequencies of mutation to genes determining harmful traits in man. Mutat Res 1967 May;4(3):339-352.

4. Kaercher T. Ocular symptoms and signs in patients with ectodermal dysplasia syndromes. Graefes Arch Clin Exp Ophthalmol 2004 Jun;242(6):495-500.

5. Nordgarden H, Storhaug K, Lyngstadaas SP, Jensen JL. Salivary gland function in persons with ectodermal dysplasias. Eur J Oral Sci 2003 Oct;111(5):371-376.

6. Daniel E, McCurdy EA, Shashi V, McGuirt WF Jr. Ectodermal dysplasia: Otolaryngologic manifestations and management. Laryngoscope 2002 Jun;112(6):962-967.

7. Mehta U, Brunworth J, Lewis RA, Sindwani R. Rhinologic manifestations of ectodermal dysplasia. Am J Rhinol 2007 Jan-Feb;21(1):55-58.

8. Motil KJ, Fete TJ, Fraley JK, Schultz RJ, Foy TM, Ochs U, Sybert VP. Growth characteristics of children with ectodermal dysplasia syndromes. Pediatrics 2005 Aug;116(2):e229-e234.

9. Sachidananda R, Nagadi A, Dass AA, Parveen Kmr BY. Anhidrotic ectodermal dysplasia presenting as atrophic rhinitis. J Laryngol Otol 2004 Jul;118(7):556-557.

10. Wiesmiller K, Keck T, Lindermann J. Atrophic rhinitis in a patient $\mathrm{w}$ anhidrotic ectodermal dysplasia. Rhinology 2005 Sep;43(3):233-235.

11. Dasgupta S, Joshi VS, Murkey NSN, Avad A, Mohanty S. Hypohydrotic (Anhydrotic) Ectodermal dysplasia - A rare cause of childhood atrophic rhinitis. Indian J Otolaryngol Head Neck Surg 2006 Apr;58(2):202-204.

12. Madana J, Yolmo D, Gopalakrishnan S, Saxena SK, Nath AK, Ilamaran V. Hypohidrotic ectodermal dysplasia with atrophic rhinitis and nasal myiasis. Int J Pediatr Otorhinolaryngol 2009 Oct;73(10):1467-1469.

13. Barman D, Mandal S, Nandi S, Banerjee P, Rashid MA. Anhidrotic ectodermal dysplasia presenting as atrophic rhinitis. J Indian Med Assoc 2011 Nov;109(11):836-837.

14. Schachner, LA.; Hansen, RC., editors. Pediatric dermatology: Ectodermal dysplasia. 2nd ed. Vol. I. New York: Churchill Livingstone; 1995. p. 361-363. 